\title{
Lídia DE Oliveira XAVIER, Carlos F. DomíngueZ Avila y Vicente FonseCA (orgs.). A Qualidade da Democracia no Brasil: Questões teóricas e metodológicas da pesquisa, vol. 4. Curitiba: CRV, 2019. 596 pp. ISBN: 978-84-444-3044-6.
}

El cuarto volumen de la obra colectiva A Qualidade da Democracia no Brasil, organizado por los profesores Lídia de Oliveira Xavier, Carlos Federico Domínguez Avila y Vicente Fonseca, emerge como un importante paso hacia la consolidación de la colección homónima, y que tiene al Centro Universitario UNIEURO de Brasilia como su principal promotor. Desde su primer volumen, editado en 2016, esta colección congrega trabajos que, en su conjunto, nos invitan a trascender las tradicionales definiciones de democracia y calidad, y a dialogar con una pluralidad de perspectivas, pluralidad esta propia de las miradas que son finas en el registro de tendencias que no siempre se individualizan con claridad. Discutir sobre calidad de la democracia nos interpela acerca del carácter complejo de su(s) significado(s) y de la necesidad de superar la linealidad en las reflexiones, y es a partir de este reconocimiento que la temática en cuestión se convierte en el hilo conductor de una variedad de estudios e investigaciones que integran hoy los cuatro volúmenes de esta colección, y que nos ofrecen un valioso aporte a los debates sobre teoría democrática y política comparada.

En particular, el cuarto volumen de esta colección cuenta con el prefacio de la profesora Renata Peixoto de Oliveira, que llama la atención acerca de la importancia de todo esfuerzo intelectual de pensar la calidad de las democracias en la contemporaneidad, y particularmente en el caso de Brasil, signado por el retorno de fuerzas políticas conservadoras al poder. Dando inicio así a este imperativo de esfuerzo intelectual materializado en el capitulado del libro en cuestión, Benício Schmidt y Lía Zanotta Machado discuten los principales desafíos de la democracia en Brasil y, por su parte, Godofredo Vidal de la Rosa debate los principios fundamentales que definen las bases del modelo de la democracia liberal en clave schumpeteriana. Gustavo López Montiel analiza la cuestión democrática a la luz de la actuación de los Poderes Judiciales en América Latina, al paso que Andrea Pozas Loyo busca hacerlo a partir de la dimensión de la eficacia constitucional. Por su parte, Rosa Alacio García trabaja la cuestión del «habitus» ciudadano y su articulación con las prácticas de participación social, y, seguidamente, Priscila de Oliveira Xavier Scudder y Eliete Borges Lopes debaten la producción de metáforas de la libertad a la luz de la teoría de la complejidad.

Por su parte, rescatando las valiosas contribuciones de la literatura latinoamericana, Hernán Toppi discute en su trabajo los aportes de Guillermo O’Donnell al tema del Estado y la democracia en América Latina, al tiempo que Jorge Francisco Aguirre Sala y José María Infante Bonfiglio discuten el concepto de accountability societal y su contribución a la calidad de la democracia. Partiendo de la necesidad de entender los actuales cambios en el sistema político brasileño, Ian Rebouças, Leonardo Bacher y Leonardo Granato efectúan su análisis echando mano a los principales conceptos de la teoría política de Nicos Poulantzas. Marco Lisi propone un ejercicio de investigación sobre la democracia intrapartidaria en Portugal, y Zilda Alves y Vicente Fonseca trabajan la implementación y evaluación de políticas públicas y su relación con la calidad de 
la democracia. También en el ámbito del Poder Ejecutivo y la administración pública, Graciele Lins Dutra centra su mirada en la gestión de la ética; Elías Nazareno presenta relevantes consideraciones acerca de políticas lingüísticas, y Gabriela Abuhab Valente centra su estudio en el diálogo entre democracia y libertad religiosa.

Seguidamente, mientras que Roberto Ellery Jr., Antônio Nascimento Jr. y George de Moura Cunha reflexionan acerca de cuáles serán los desafíos enfrentados por Brasil en la búsqueda del crecimiento económico, María Paula Meneses discute el concepto de sociedad civil a la luz de las posibilidades de la llamada justicia cognitiva en Mozambique. Retomándose nuevamente el pensamiento de O'Donnell en este volumen, el trabajo de Alicia Hernández de Gante presenta relevantes reflexiones sobre el caso mexicano a partir de las enseñanzas del mencionado autor. Posteriormente, Jéssica de Sousa Rosa y Silvia Guimarães discuten salud indígena y democracia en Brasil bajo una perspectiva antropológica, y Ángeles Castaño Madroñal y Juan Carlos Gimeno Martín presentan una discusión acerca de la descolonización de las metodologías en las llamadas «antropologías de orientación pública». Izabel Bacellar Zaneti, Fracisco Campos y Sandro Dutra e Silva centran su estudio en los impactos locales de la Política Nacional de Residuos Sólidos en Brasil. Ofreciendo destacadas contribuciones para la reflexión en el campo de la política exterior y la integración regional, los trabajos de Carlos Eduardo Vidigal y Raúl BernalMeza, de Paulo Velasco Jr. y de José Alejandro Barrios Díaz y Arthur Banzatto debaten acerca del devenir y estado actual del Mercosur, y efectúan consideraciones acerca de la llamada «cláusula democrática» y de los nuevos rumbos de la Política Exterior brasileña. Finalmente, Marcelo Nobis y Carlos Federico Domínguez Avila realizan un estudio de caso sobre acceso a la justicia y calidad de la democracia en Brasil, y Henry Ani Kifordu analiza, en clave crítica, la circulación de las elites en el régimen democrático.

Tal como el profesor Renato Zerbini Ribeiro Leão ha resaltado en el epílogo de este cuarto volumen objeto de recensión, la colección A Qualidade da Democracia no Brasil viene consolidándose como una relevante herramienta para combinar ideas y perspectivas acerca de la política. Por su carácter amplio y «poroso», este libro deja aflorar nuevos interrogantes y abre caminos, provoca la discusión de argumentos y, sobre todo, nos invita a participar de un debate que está en marcha. Cada uno de los textos que integran este volumen, cuidadosamente elaborados por sus autores, nos muestra indagaciones en marcha, resultados y nuevos cuestionamientos, apuntando hacia la necesidad de pensar y repensar las variadas aristas y posibilidades de una totalidad social compleja.

Leonardo GRANATO Universidade Federal do Rio Grande do Sul 